\title{
ANÁLISE DA CONCORRÊNCIA BANCÁRIA NO BRASIL PÓS PLANO REAL
}

\author{
Oscar Felipe Rodrigues Ribeiro (UEM)' \\ Julyerme Mattheus Tonin $(\text { UEM })^{2}$
}

\section{Resumo}

Após a implementação do Plano Real em 1994, o setor bancário brasileiro passou por uma profunda mudança dada a necessidade de adequação ao contexto de baixa inflação, resultando em perda das receitas provenientes do float bancário. As principais mudanças ocorridas foram um amplo processo de consolidação bancária, com fusões e aquisições, diminuição significativa de bancos com controle estatal e a facilitação para a entrada de instituições estrangeiras no mercado financeiro nacional. A fim de elucidar tais fatos utilizaram-se índices de concentração e uma análise empírica de dados, em que se constatou que houve uma mudança estrutural na indústria financeira, sendo que, o setor público perde grande parte da sua participação relativa, em contrapartida, o setor privado aumentava sua participação, principalmente, com a entrada de bancos estrangeiros no sistema financeiro nacional.

Palavras-Chave: Concentração Bancária, Índices de concentração, Setor Bancário brasileiro

Classificação JEL: G15, G30, G34

\section{INTRODUÇÃO}

Com o sucesso da estabilidade de preços que adveio com o Plano Real, o setor bancário teve que se adequar a uma nova conjuntura econômica

Graduado em Economia na Universidade Estadual de Maringá - Oscar_ribeiro_3@hotmail.com

2 Professor Assistente do Departamento de Economia na Universidade Estadual de Maringá - julyermetonin@gmail.com 
e passar por um processo de reestruturação, dado que esse setor perdera receitas originadas com as operações de floating. À luz desse fato, alguns bancos não conseguiram se reestruturar e acabaram sendo incorporados por outras instituições e para promover esse processo o governo criou incentivos para viabilizar as fusões e aquisições no sistema bancário.

Além disso, houve as privatizações dos bancos públicos com intuito de incentivar a concorrência e diminuir a participação do Estado. Mendonça (2006) sintetiza as mudanças de ordem institucional e no ambiente em que as instituições bancárias atuam em quatro grupos: processo de liberalização financeira; redução da inflação; movimento de fusões e aquisições e reestruturação das instituições financeiras públicas federais.

Nesse sentido, De Paula e Marques (2006) destacam que, a busca por solidez do setor bancário muitas vezes acaba entrando em conflito com o objetivo de estímulo à competitividade. Ademais, na defesa da concorrência no Brasil há um conflito de competências entre o CADE e o BACEN. Grau (2005) destaca-se que cabe ao CADE analisar as questões ligadas à concorrência em geral, e ao BACEN seria responsável por aspectos relacionados ao risco sistêmico ${ }^{3}$.

Nesse sentido, no presente estudo, busca-se avaliar em que medida, a diminuição no número de instituições bancárias, ocorridas principalmente pelo processo de Fusões e Aquisições (F\&A) Pós-Plano Real, conjuntamente com a abertura financeira para o capital estrangeiro no setor, contribuir para a concentração do setor, no decorrer das décadas de 1990 e 2000. Em uma análise prévia do mercado busca-se identificar qual a representativa dos bancos brasileiros no total das instituições bancárias do país.

Quanto aos índices de concentração, serão utilizados os índices de Hirschman-Herfindal $(\mathrm{HH})$, as razões de concentração $\left(\mathrm{CR}_{\mathrm{K}}\right)$, o índice de entropia de Theil (T), o índice de Hall-Tideman (HTI), o índice de Concentração Industrial Compreensível (CCI) o índice de Hause $\left(\mathrm{H}_{\mathrm{m}}\right)$ e o índice de Hannah e Kay (HKI) para avaliar o ambiente concorrencial das firmas bancárias no Brasil.

Por meio de Silveira Datz (2002, p.3) temos que risco sistêmico foi definido pelo Comitê de Basiléia "como sendo aquele em que a inadimplência de uma instituição para honrar seus compromissos contratuais pode gerar uma reação em cadeia, atingindo grande parte do sistema financeiro. Esta definição pressupõe elevada exposição direta entre as instituições, de modo que a falência de qualquer uma inicie um verdadeiro 'efeito cascata' sobre o sistema." 
Distinguindo-se dos trabalhos publicados sobre o tema, como De Paula e Marques (2006), Jorge-Neto, Araújo e Ponce (2006), Botelho (2006) e Nasser (2008), entre outros, o presente estudo busca realizar uma análise comparativa da concentração bancária nas décadas de 1990 e 2000, amplia a quantidade de índices utilizados e adota um ajuste no índice HHI para contornar o problema detectado por Srivastava e Aggarwal (1979).

\section{CONSOLIDAÇÃO BANCÁRIA NO BRASIL}

O processo de consolidação bancária no Brasil teve início no final da década de 1980, porém ocorreu com maior intensidade após 1995, com um alto grau de participação do setor público. Em meados da década de 1990, em um quadro de elevada incerteza devido ao período de descontrole inflacionário, De Paula (1997) destaca que a firma bancária tomava uma postura conservadora, aumentando a composição de ativos na forma mais líquida. Nesse contexto, De Paula (1998) destaca que as receitas eram obtidas em operações de floating 4 e com altos spreads nas intermediações financeiras.

O sucesso do Plano Real na estabilização dos preços teve impacto na taxa de lucro dos bancos, com a redução das receitas de floating. Nesse sentido, De Paula (1998) destaca que as operações de floating caíram praticamente a zero em proporção do PIB, em 1995. Nesse contexto, os bancos tiveram que buscar outros meios para manter a taxa de lucro. Puga (1999) destaca que, em um primeiro momento houve um aumento das operações de crédito, porém essa estratégia foi interrompida devido ao aumento da inadimplência no segundo semestre de 1995, dada a elevação da taxa de juros com a crise do México. Cysne e Costa (1996) destacam que a instabilidade da política creditícia deve-se a onda consumista da população, em que desconsiderou-se que os rendimentos nominais não mais aumentariam como antes, resultando em inadimplência por parte dos consumidores.

Dado que alguns bancos não conseguiram se adequar ao novo cenário, o Governo passa a atuar no setor para sanar o risco sistêmico. Uma das primeiras medidas adotadas foi o enquadramento do setor bancário brasi-

De Paula (1998, p.9) destaca que as receitas obtidas com floating consistiam basicamente na manutenção no passivo dos bancos de saldos não-remunerados que, aplicados, rendiam, pelo menos, algo próximo da correção monetária. 
leiro às recomendações do Acordo de Basiléia (1988)5. Em 17/08/1994 por meio da resolução n. ${ }^{\circ} 2.099$ o governo estipulou uma exigência de capital mínimo (retenção de $8 \%$ das operações a vista dos bancos). Para De Paula e Marques (2006) essas exigências dificultaram a sobrevivências de bancos de pequeno e médio porte.

Para suprir as perdas e reduzir os custos, Barbachan e Fonseca (2004) destacam que os bancos realizaram cortes de pessoal e investiram em tecnologia de informação, sendo que, entre 1994 e 1998 o número de agências reduziu-se em $8 \%$, em contrapartida, os postos de auto-atendimento (atendimento eletrônico) quintuplicaram entre 1994 e 2001.

O Governo volta a atuar no setor, por meio da carta de exposição de Motivos n. ${ }^{\circ} 311$ em 23/08/1995 que demonstrava o interesse e criava a base legal para a entrada e/ou ampliação de capital financeiro estrangeiro no sistema financeiro nacional. Em 03/11/1995, por meio da Medida Provisória n. ${ }^{\circ} 1.179$ e da Resolução n. ${ }^{\circ} 2.208$ o Governo criou o Programa de Estímulo à Reestruturação e Fortalecimento do Sistema Financeiro Nacional (PROER). O PROER foi criado visando, principalmente, a ordenação da fusão e incorporação de bancos a partir de regras estipuladas pelo Banco Central. Por sua vez, a Resolução n. ${ }^{\circ} 2.211$ criou o Fundo Garantidor de Crédito ${ }^{6}$.

Todas essas medidas, somado a medida provisória $\mathrm{n}^{\circ} 1.182$ deram ao Banco Central aparato legal para conduzir o sistema financeiro e poder agir de forma preventiva contribuindo para reestruturação e consolidação do setor. A respeito dos bancos públicos, em agosto de 1996, o governo iniciou o Programa de Incentivo para a Reestruturação do Sistema Financeiro Estatal (PROES), com a finalidade de sanear o sistema financeiro estadual e, principalmente, reduzir a participação do Estado no Sistema Bancário Brasileiro. Para Puga (1999, p.424) dos 35 bancos estaduais existentes em 1996, 10 foram extintos, 6 privatizados pelos governos estaduais, 7 federali-

O acordo de Basiléia consistia em um conjunto de regras que desde 1988, tornou-se referência global para a regulação bancária. Seus objetivos eram: i) minimizar os riscos de insucesso dos bancos; ii) garantir a solvência e a liquidez do Sistema Financeiro Internacional; iii) uniformizar normas aplicáveis às instituiç̧ões financeiras e iv) estabelecer limites operacionais para os bancos internacionalmente ativos.

6 É um fundo criado para oferecer garantia a determinados créditos mantidos por correntistas ou investidores contra instituições financeiras submetidas a regime especial de liquidação extrajudicial (DE PAULA e MARQUES, 2006, p.25I). 
zados para posterior privatização, 5 reestruturados com recursos do PROES e apenas 3 que não participaram do programa.

Sobre o montante de recursos do PROES, Puga (1999) mostrou que foram emitidos em títulos federais aproximadamente US\$ 48 bilhões (6\% do PIB) a fim de sanar os bancos estaduais. Desse total, US\$ 26 bilhões foram destinados ao estado de São Paulo para que liquidasse sua dívida com o Banespa; US\$ 8 bilhões foram destinados para a Nossa Caixa; US\$ 4 bilhões para o Banestado; US\$ 1,5 bilhão para o Bemge; e US\$ 3 bilhões para o Banerj e para o Banrisul.

Os resultados dessa atuação do Governo são visíveis na adoção do regime de câmbio flutuante (janeiro de 1999) e do regime de metas de inflação (junho de 1999). Para Averbug e Giambiagi (2000) o sistema financeiro encontrava-se menos vulnerável nesse período. Bem como, em outro momento, na "crise eleitoral" de 2002, não houve uma crise sistêmica nem mudanças abruptas na quantidade e composição dos bancos.

Outro fato importante que marcou a década analisada foi que em 26 de junho de 2004 o Comitê de Supervisão Bancária de Basiléia (BCBS) criou o Novo Acordo de Capitais (Basiléia II), que tinha o intuito de corrigir o que o primeiro havia errado ou conseguir os objetivos que não foram atingidos. $\mathrm{O}$ acordo trazia em si um esboço do que o seu antecessor havia estipulado, mas "iria mais longe, no sentido de fortalecer a solidez e estabilidade do sistema bancário internacional" (BCBS, 2003, p.1).

Enfim, De Paula e Marques (2006, p.237) observa que inicialmente o processo de F\&A bancárias foi do tipo "consolidação como resposta a estruturas bancárias ineficientes ou frágeis" só foi possível graças aos programas PROER/PROES. Porém o maior grau de F\&A que se tem no sistema financeiro nacional a partir de meados de 1997 deu-se pelo fato de que o sistema tornou-se mais sólido e foi necessária uma adequação por parte dos bancos nacionais a uma maior concorrência, tanto por parte da inserção de bancos estrangeiros, o que promoveu uma maior eficiência, como por parte de uma menor participação do Estado o que deixou o mercado mais amplo para os bancos privados. Por fim, a Tabela 1 sintetiza as principais fusões e aquisições que ocorreram após a implementação do Plano Real. 
Tabela 1. Principais Fusões e Aquisições bancárias pós Plano Real

\begin{tabular}{|l|l|l|l|l|l|}
\hline $\begin{array}{l}\text { Instituição } \\
\text { Vendida }\end{array}$ & $\begin{array}{l}\text { Instituição } \\
\text { Compradora }\end{array}$ & Data & $\begin{array}{l}\text { Instituição } \\
\text { Vendida }\end{array}$ & \multicolumn{1}{l|}{$\begin{array}{l}\text { Instituição } \\
\text { Compradora }\end{array}$} & Data \\
\hline Década de 1990 & \multicolumn{5}{|l|}{ Década de 2000 } \\
\hline B. Nacional & B. UniB. & Nov/1995 & Credibanco & Unibanco & Jun/2000 \\
\hline B. Econômico & B. Excel & Abr/1996 & Banestado & ITAÚ & Out/2000 \\
\hline B. Mercantil & B. Rural & Mai/1996 & Banespa & Santander & Nov/2000 \\
\hline B.Banorte & B. Bandeirantes & Jun/1996 & Bandeirantes & Unibanco & Dez/2000 \\
\hline B. Martinelli & B. Pontual & Ago/1996 & Paraiban & ABN Amro & Nov/2001 \\
\hline B. United & $\begin{array}{l}\text { B. Antonio } \\
\text { Queiroz }\end{array}$ & Ago/1996 & BEG/Goiás & ITAÚ & Dez/2001 \\
\hline B. Bamerindus & HSBC & Abr/1997 & BEA/Amazonas & Bradesco & Jan/2002 \\
\hline BaneRJ & Itaú & Jun/1997 & Mercantil de S.P. & Bradesco & Mar/2002 \\
\hline Credireal & BCN & Ago/1997 & BBA Creditanstalt & ITAÚ & Set/2002 \\
\hline B.G. de Comércio & Santander & Dez/1997 & Bilbao Vizcaya & Bradesco & Jun/2003 \\
\hline Noroeste & Santander & Dez/1997 & Sudameris & ABN Amro & Dez/2003 \\
\hline Meridional & $\begin{array}{l}\text { Bozano, } \\
\text { Simonsen }\end{array}$ & Set/1998 & BEM/Maranhão & Bradesco & Fev/2004 \\
\hline BCN & Bradesco & Jun/1998 & Lloyds Bank & HSBC & Mar/2004 \\
\hline Dibens & Santander & Jun/1998 & BNL & Unibanco & Jun/2004 \\
\hline Baneb & Bradesco & Jun/1998 & Bankboston & ITAÚ & Set/2006 \\
\hline Bandepe & ABN Amro & Nov/1998 & Unibanco & ITAÚ & Dez/2008 \\
\hline B. Real & ABN Amro & Jun/1999 & ABN Amro & Santander & Dez/2008 \\
\hline Pontual (BCN) & Bradesco & Dez/1999 & & & \\
\hline
\end{tabular}

Fonte: Banco Central do Brasil (2010), De Paula e Marques (2006) e Faria Júnior, De Paula e Marinho (2007). Elaboração e adaptação própria.

No comparativo das fusões e aquisições ocorridas entre as décadas de 1990 e 2000, verifica-se que apesar dos incentivos do PROER se limitarem nas operações dos bancos Nacional, Econômico, Mercantil, Banorte, Martinelli, United e Bamerindus, totalizando US\$ 21 bilhões (PUGA, 1999), o processo de consolidação manteve o ritmo acentuado até 2004, sendo 17 fusões e aquisições na década de 2000, contra 18 na década de 1990. As fusões e aquisições mais recentes, apesar do menor número, são relevantes, na medida em que envolvem instituições com grandes participações no setor. 


\section{METODOLOGIA}

A fim de testar a hipótese de que aumentou a concentração bancária no Brasil no decorrer das décadas de 1990 e 2000, o presente estudo apresenta o cálculo de índices de concentração econômica, sendo utilizado para esse fim as seguintes variáveis: Patrimônio Líquido; Ativos Totais; Operações de Crédito; Depósitos Totais. Os índices calculados para testar a hipótese de que o setor bancário sofreu alteração ao decorrer do período proposto são descritos nos próximos parágrafos.

\section{1 Índices de concentração}

A Razão de Concentração $\left(\mathrm{CR}_{\mathrm{K}}\right)$ é a medida de concentração mais comumente usada na literatura que trata sobre o tema, a mesma mede a participação das $n$ primeiras firmas no mercado como um todo, seu intervalo fica entre zero e um, e quanto mais se aproxima de um, mais concentrado é o setor (GEORGE e JOLL, 1983). No presente estudo pretende-se calcular as seguintes razões de concentração: $C R(5), C R(10)$ e $C R(20)$.

$$
C R(k)=\sum_{i=1}^{k} s_{i} \quad \text { com } \quad 0<C R_{K} \leq 1
$$

em que, $k$ corresponde ao número de firmas com maior concentração consideradas na análise e $S_{i}$ representa a participação de cada firma na indústria.

O índice de Hirschman-Herfindahl (HHI), que se observa na Equação 2, também é uma medida utilizada comumente, na condição de equilíbrio de Cournot $^{7}$. Esse índice leva em conta todas as firmas do mercado, sendo que, o intervalo deste índice é de $1 / \mathrm{n}$ a 1 , sendo que, o limite superior deste índice expressa o extremo monopólio em que apenas uma empresa domina todo o mercado (RESENDE e BOFF, 2002).

$$
H H I=\sum_{i=1}^{n} s_{i}^{2} \quad \text { com } \quad 1 / n \leq H H I \leq 1
$$

Segundo Resende e Boff (2002), considerando o equilíbrio de um oligopólio homogêneo em competição de Cournot, o Índice de Hirschman-Herfindahl guarda estreita relação com o grau de lucratividade da indústria em questão. Nesse sentido, a obtenção de elevados índices de concentração aumentam as chances das empresas pertencentes à indústria comportarem-se como oligopólio. 
em que, $S_{i}$ representa a participação da i-ésima firma e $n$ o número total de firmas da indústria.

De acordo com Srivastava e Aggarwal (1979) ${ }^{8}$ citado por Nasser (2008), uma limitação do índice HHI é de que, à medida que $n$ muda, o limite inferior $(1 / \mathrm{n})$ também se modifica, sendo assim as comparações intertemporais ficam prejudicadas fazendo-se necessário ajuste no índice, quando o número de firmas ao longo do período estudado estiver variando.

Para fazer uma análise comparativa, em um setor em que ocorre a variação no número de companhias, Resende (1994) sugere um ajuste no índice HHI, fazendo que o intervalo desse índice passe a variar entre 0 e 1 , assim, o mais distante de zero denota um mais alto grau de concentração.

$$
H H I^{*}=\frac{1}{n-1}(n \times H H I-1) \quad n>1 \quad \text { assim, } 0<H H I^{*} \leq 1
$$

Outra medida comumente utilizada é a Entropia de Theil (T). Este índice pode ser interpretado como sendo uma medida inversa da concentração. Esta medida pondera a participação de cada firma pelo logaritmo de $n$. O intervalo é igual ao intervalo da $\mathrm{CR}_{\mathrm{K}}$, porém analisa-se de forma inversa, ou seja, quando se aproxima de zero mais concentrado é a indústria (RESENDE e BOFF, 2002).

$$
T=\frac{1}{\ln (n)} \sum_{i=1}^{n} s_{i} \ln \left(1 / s_{i}\right) \quad \text { com } \quad 0<T \leq 1
$$

Há também o Índice Hall-Tideman (HTI) ${ }^{9}$, que incorpora na análise a posição de cada banco no ranking dando ênfase ao número de bancos no setor. Para Bikker e Haaf (2002) esse índice mostra também a condição de entrada de um banco nessa indústria, pois um grande número de bancos revela poucas restrições enquanto um pequeno número de bancos cria barreiras razoáveis à novos entrantes nesse segmento. Para Botelho (2006), para tal utiliza-se a variável $i$ que têm seus valores segundo a ordenação do tamanho dos bancos, desde o maior $(i=1)$ até o menor $(i=n)$. Em suma,

8 Srivastava, D. K.; Aggarwal, P. K. Measuring Tax Revenue Centralization in Federal Fiscal Systems: A Case Study of India, Public Finance, 34, issue 3, p. 414-33, 1979.

9 Bikker e Haaf (2002) destacam que existe o índice de Rosenbluth (RI) que é equivalente ao índice de Hall-Tideman, porém a ponderação i atribui um peso maior aos menores bancos na análise. Dada a similaridade entre os índices, o mesmo não foi incluso no escopo desse estudo. 
o market-share da instituição financeira recebe peso igual a sua ordem na construção do índice, da seguinte forma:

$$
H T I=\frac{1}{2 \sum_{s_{i}}^{n} i s_{i}-1} \quad \text { com } \quad 0<H T I \leq 1
$$

Por sua vez, o índice de Concentração Industrial Compreensível (CCI), sigla proveniente da definição em inglês "Comprehensive Industrial Concentration Index", tem a função de refletir qual a concentração absoluta e relativa da indústria estudada, sendo que, este índice surgiu a partir de medidas de dispersão e as medidas discretas de concentração (BOTELHO, 2006, p.7-8).

$$
C C I=s_{i}+\sum_{i=2}^{n} s_{i}^{2}\left[1+\left(1-s_{i}\right)\right] \quad \text { com } 0<C C I \leq 1
$$

A medida denominada índice de Hause $\left(H_{m}\right)$ fornece evidências de que com o aumento de $n$, a tendência de maior concorrência será menor para valores menores de $\alpha$, sendo que o parâmetro $\alpha$ capta efeitos de conluio num modelo oligopolista (NASSER, 2008, p. 44).

$$
H_{m}\left(\alpha ;\left\{s_{i}\right\}\right)=\sum_{i=1}^{n} s_{i}^{2-\left[s_{i}\left(H H I-s_{i}^{2}\right)\right]^{\alpha}} \quad \operatorname{com} \quad 0<H_{m} \leq 1
$$

O índice de Hannah e Kay (HKI) é um parâmetro de elasticidade que se destina a refletir as mudanças na concentração de um mercado, como resultado de entrada ou saída de bancos na indústria, sendo expresso da seguinte forma:

$$
H K I=\left(\sum_{i=1}^{n} s_{i}^{\alpha}\right)^{\alpha / 1-\alpha} \operatorname{com} \alpha>0 ; \alpha \neq 1 \text { e } 1 / S_{i} \leq H K I n
$$

No qual $\alpha$ admite valores positivos e corresponde ao parâmetro de elasticidade específica que depende do peso que se queira atribuir, ou às participações mais altas ou as mais baixas (BIKKER e HAFF, 2000, p. 6). $\mathrm{O}$ índice assume valor igual a 1 no caso de máxima desigualdade e $n^{(1-\alpha)}$ quando cada firma analisada possuir a mesma participação. Nesse trabalho, será utilizado o valor de $\alpha=2$ que retorna ao valor recíproco do $\mathrm{HHI}^{10}$, ou seja, $H K I=1 / H H I$.

10 O valor recíproco $[\mathrm{I} / \mathrm{HHI}$ do índice mostra o número de participante do setor analisado, ou seja, o número "equivalente" de participantes no mercado. 
No trabalho de De Paula e Marques (2006) foi calculado o HH para alguns países emergentes, e como resultado de pesquisa constatou-se que na América Latina em geral, o processo de consolidação bancária foi intenso na década de 1990, com grande participação do governo nesse processo. Jorge-Neto, Araújo e Ponce (2006) calcularam os índices $\mathrm{CR}_{3}, \mathrm{CR}_{5}, \mathrm{CR}_{10}$, HHI, HTI e Theil para os depósitos totais, ativos totais e as operações de crédito. Esses autores concluíram que os ativos e depósitos tornaram-se mais concentrado entre os 10 maiores bancos no Brasil, fato que não foi constatado na análise das operações de crédito.

Botelho (2006), por sua vez, calculou os índices de concentração $\mathrm{CR}_{3}$, $\mathrm{CR}_{5}$ e $\mathrm{CR}_{10}$, HHI, HTI, CCI e Theil para o Brasil e Portugal, utilizando as variáveis: depósitos totais, ativos totais e operações de crédito. $\mathrm{O}$ autor encontrou índices baixos para os dois países, chegando a conclusão de que no Brasil, a indústria é menos concentrado que Portugal. Cabe destacar também o estudo feito por Nasser (2008), utilizando os índices $\mathrm{CR}_{3}, \mathrm{CR}_{5} \mathrm{e}$ $\mathrm{CR}_{10}$, HHI, HTI para analisar os depósitos totais, demonstrando um aumento da concentração do setor no período de análise proposto pelo autor, que foi entre junho de 2001 a dezembro de 2007.

\section{2 fonte de dados}

No presente estudo, para o cálculo dos índices selecionados, no período de junho de 1990 a dezembro de 2009, utilizou-se as contas de Patrimônio Líquido, Ativos Totais, Operações de Crédito e Depósitos Totais, divulgadas semestralmente pelo Banco Central do Brasil (BCB, 2010). Cabe ressaltar que a variável Ativo Total, abrange o ativo circulante e realizável a longo prazo juntamente como o ativo permanente, enquanto que os Depósitos Totais compreendem os depósitos em poupança somados aos depósitos à vista, juntamente com os depósitos a prazo. Cabe destacar que, os depósitos a prazo são, em geral, a maior parte do passivo das instituições bancárias.

\section{RESULTADOS E DISCUSSÕES}

Primeiramente, cabe fazer uma análise da composição do Sistema Financeiro Nacional, no que diz respeito à participação relativa das instituições 
financeiras. Observa-se, uma queda significativa da participação dos bancos públicos (excluindo-se Caixa Econômica Federal e Banco do Brasil). Nesse sentido, a atuação do governo em desestatizar este setor teve êxito, pelo menos a despeito da participação do setor público, que diminuiu bastante.

Em contrapartida, os bancos privados com controle estrangeiro aumentam significativamente sua participação relativa, em 19,44 p.p. no comparativo entre os anos de 1995 e 2000, no tocante as operações de crédito. Comportamento similar é verificado para os ativos totais, depósitos e patrimônio líquido dessas instituições. Por fim, cabe ressaltar que os bancos privados nacionais apresentam a principal participação relativa, especialmente em termos de patrimônio líquido (Tabela 2).

Tabela 2. Participação de Cada Segmento Bancário no Sistema Financeiro Nacional (períodos e indicadores selecionados)

\begin{tabular}{lccccc}
\hline Período* & $\mathbf{1 9 9 3}$ & $\mathbf{1 9 9 5}$ & $\mathbf{2 0 0 0}$ & $\mathbf{2 0 0 5}$ & $\mathbf{2 0 0 9}$ \\
\hline Crédito & $19,86 \%$ & $23,46 \%$ & $5,12 \%$ & $4,05 \%$ & $3,20 \%$ \\
Ativo & $13,41 \%$ & $21,90 \%$ & $5,62 \%$ & $5,09 \%$ & $2,13 \%$ \\
Depósito & $17,25 \%$ & $16,07 \%$ & $7,36 \%$ & $5,98 \%$ & $2,42 \%$ \\
Patrimônio & $15,02 \%$ & $12,41 \%$ & $5,66 \%$ & $4,74 \%$ & $1,91 \%$ \\
\hline \multicolumn{5}{c}{ Bancos Privados Nacionais } \\
\hline Crédito & $31,49 \%$ & $31,79 \%$ & $34,53 \%$ & $40,84 \%$ & $37,68 \%$ \\
Ativo & $40,67 \%$ & $39,18 \%$ & $35,23 \%$ & $43,12 \%$ & $51,61 \%$ \\
Depósito & $38,80 \%$ & $36,40 \%$ & $33,93 \%$ & $41,61 \%$ & $48,55 \%$ \\
Patrimônio & $48,23 \%$ & $49,21 \%$ & $50,33 \%$ & $54,15 \%$ & $63,90 \%$ \\
\hline \multicolumn{5}{c}{ Bancos $\%$} \\
\hline Crédito & Bancos com Controle Estrangeiro & \\
Ativo & $6,56 \%$ & $5,72 \%$ & $25,16 \%$ & $26,37 \%$ & $19,06 \%$ \\
Depósito & $8,35 \%$ & $8,38 \%$ & $27,41 \%$ & $22,89 \%$ & $17,80 \%$ \\
Patrimônio & $4,83 \%$ & $5,40 \%$ & $21,14 \%$ & $20,27 \%$ & $16,98 \%$ \\
\hline
\end{tabular}




\begin{tabular}{lrrrrr}
\hline \multicolumn{5}{c}{ Banco do Brasil } \\
\hline Crédito & $19,12 \%$ & $15,96 \%$ & $10,95 \%$ & $18,46 \%$ & $24,83 \%$ \\
Ativo & $22,93 \%$ & $13,91 \%$ & $15,63 \%$ & $15,36 \%$ & $17,44 \%$ \\
Depósito & $11,08 \%$ & $17,59 \%$ & $17,05 \%$ & $16,51 \%$ & $19,25 \%$ \\
Patrimônio & $24,93 \%$ & $11,82 \%$ & $9,89 \%$ & $9,30 \%$ & $7,67 \%$ \\
\hline \multicolumn{5}{c}{ Caixa Econômica Federal } \\
\hline Crédito & $22,78 \%$ & $22,63 \%$ & $23,00 \%$ & $8,01 \%$ & $12,66 \%$ \\
Ativo & $14,51 \%$ & $16,40 \%$ & $15,35 \%$ & $12,05 \%$ & $9,57 \%$ \\
Depósito & $27,92 \%$ & $24,33 \%$ & $19,49 \%$ & $14,26 \%$ & $11,43 \%$ \\
Patrimônio & $4,04 \%$ & $12,04 \%$ & $3,82 \%$ & $4,39 \%$ & $2,79 \%$ \\
\hline \multicolumn{5}{c}{ Cooperativas de Crédito } \\
\hline Crédito & $0,19 \%$ & $0,44 \%$ & $1,24 \%$ & $2,27 \%$ & $2,57 \%$ \\
Ativo & $0,13 \%$ & $0,23 \%$ & $0,76 \%$ & $1,49 \%$ & $1,45 \%$ \\
Depósito & $0,12 \%$ & $0,21 \%$ & $1,03 \%$ & $1,37 \%$ & $1,37 \%$ \\
Patrimônio & $0,50 \%$ & $1,44 \%$ & $1,99 \%$ & $2,86 \%$ & $2,35 \%$
\end{tabular}

Fonte: Elaboração própria com base em Banco Central (2010)

* Bancos Públicos, excluindo Caixa Econômica Federal e Banco do Brasil

Parte-se então para o cálculo dos índices de concentração. Primeiramente analisar-se-á os Ativos Totais, tendo em vista que o mesmo é a principal variável no ranking dos bancos, elaborado pelo Banco Central. Na Figura 1 observa-se que no início da análise, o sistema bancário brasileiro encontrava-se em um patamar de concentração levemente moderada, levando em conta a classificação adotada pelo departamento de justiça norte-americano. Por exemplo, o HHI* encontrava-se em 0,11 e 0,12 entre 1990 e $1991^{11}$, a partir de então, o setor torna-se mais competitivo (Figura 1.1). Outro ponto fundamental a ser ressaltado, é o aumento expressivo que ocorre nas razões de concentração, especialmente o CR(5), a partir de junho de 2008, período

' $O$ departamento de justiça norte americano, de acordo com Magalhães et al. (2008) segue as seguintes interpretações: uma indústria competitiva sem empresas dominantes $\left(H H l^{*}<0,1\right)$; indústria com concentração moderada $\left(0,\left|<H H l^{*}<0,\right| 8\right)$; indústria com concentração alta $\left(\left.H H\right|^{*}>0,18\right)$. 
este marcado pela fusão/aquisição envolvendo quatro grandes bancos, o Itaú com o Unibanco e Santander com o ABN Amro, o que fizera com que o Ativo Total dessas instituições, que já faziam parte do CR(5), aumentasse e assim tornando-o mais representativo neste índice (Figura 1.2).

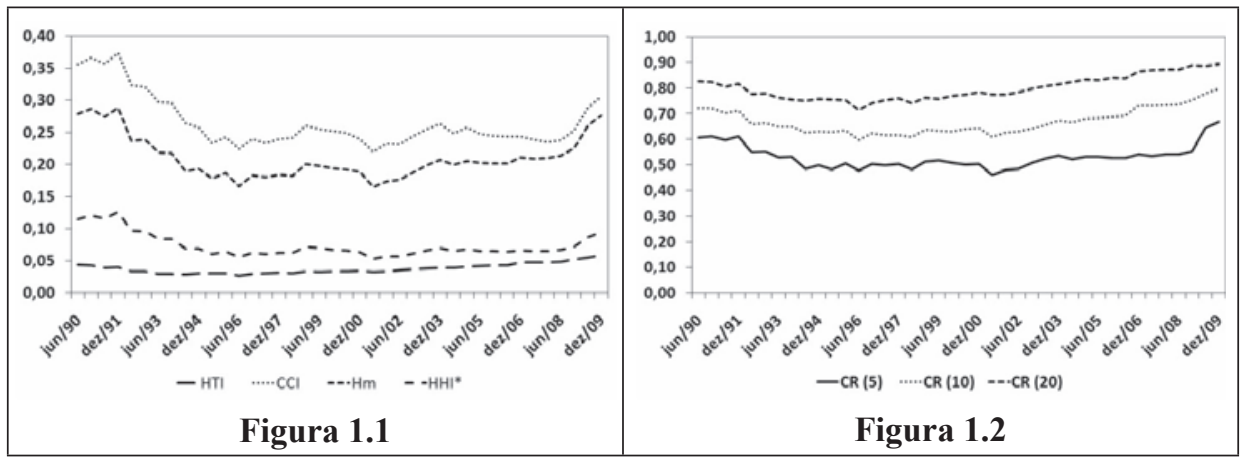

Figura 1. Índices e Razões de Concentração para os Ativos Totais Fonte: Resultados da pesquisa.

No cálculo dos índices de Theil (Figura 2.1) e de Hannah-Kay (Figura 2.2) o resultado é similar aos encontrados nos outros índices, porém de forma inversa, ou seja, no início da década de 1990 ambos os índices encontravam-se baixos, o que denota maior concentração no sistema bancário, porém no decorrer da década até início da década de 2000, os índices apresentaram aumentos gradativos, e por fim, ao longo dos últimos anos, o T e o HKI voltaram a patamares mais baixos e com isso, houve um aumento da concentração bancária.

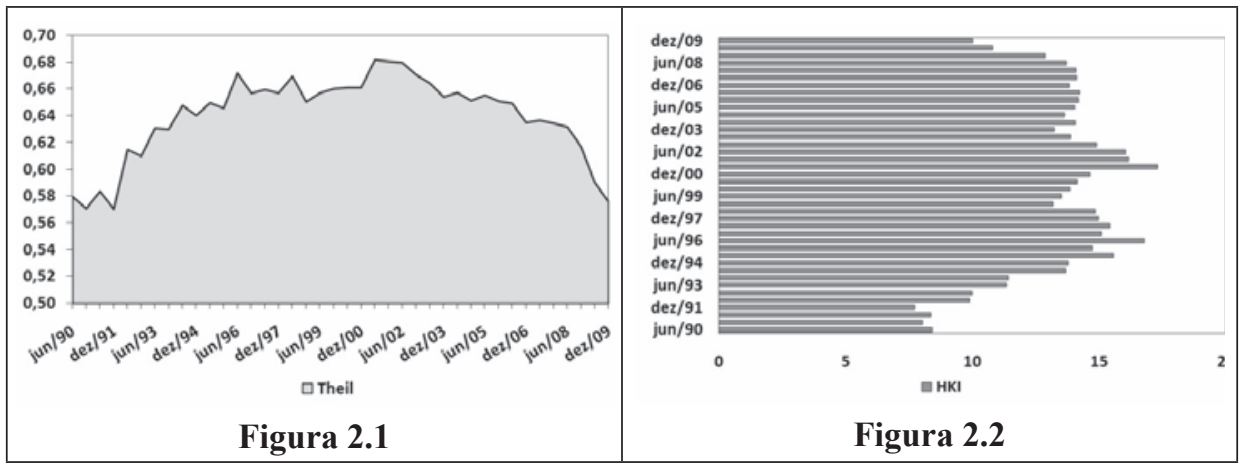

Figura 2. Índice de Theil e de Hannah-Kay para os Ativos Totais

Fonte: Resultados da pesquisa. 
Na análise do patrimônio líquido, verifica-se uma desconcentração do sistema bancário brasileiro no decorrer da década de 1990 até meados da década de 2000. A maioria dos índices analisados $\left(\mathrm{CR}_{10}, \mathrm{HHI}^{*}, \mathrm{HKI}, \mathrm{H}_{\mathrm{m}}\right.$, CCI e Theil) indicam que essa desconcentração ocorreu até junho de 2002, sendo que a partir de então, há uma tendência de concentração do setor. Cabe destacar que as razões de concentração dos 10 e 20 maiores bancos em 2009 são superiores ao observado no início da análise.

Tabela 3. Índices de concentração baseado no Patrimônio Líquido das Instituições Bancárias - Períodos Selecionados.

\begin{tabular}{|c|c|c|c|c|c|c|c|c|c|}
\hline & Dez/90 & Dez/95 & Dez/00 & Jun/02 & Dez/05 & Dez/06 & Dez/07 & Dez/08 & Dez/09 \\
\hline $\mathrm{CR}_{5}$ & 0,555 & 0,435 & 0,425 & 0,361 & 0,398 & 0,456 & 0,431 & 0,483 & 0,539 \\
\hline $\mathrm{CR}_{10}$ & 0,665 & 0,565 & 0,552 & 0,546 & 0,591 & 0,658 & 0,627 & 0,694 & 0,739 \\
\hline $\mathrm{CR}_{20}$ & 0,787 & 0,678 & 0,683 & 0,706 & 0,772 & 0,809 & 0,799 & 0,839 & 0,863 \\
\hline HHI* & 0,086 & 0,043 & 0,039 & 0,033 & 0,041 & 0,049 & 0,044 & 0,056 & 0,066 \\
\hline HTI & 0,032 & 0,020 & 0,023 & 0,026 & 0,032 & 0,036 & 0,035 & 0,042 & 0,047 \\
\hline Theil & 0,629 & 0,721 & 0,741 & 0,749 & 0,720 & 0,691 & 0,706 & 0,664 & 0,636 \\
\hline $\mathrm{CCl}$ & 0,302 & 0,185 & 0,167 & 0,151 & 0,178 & 0,196 & 0,181 & 0,218 & 0,239 \\
\hline HKI & 11,09 & 21,36 & 22,62 & 25,83 & 21,23 & 18,16 & 19,91 & 16,16 & 13,93 \\
\hline$H_{m}$ & 0,224 & 0,136 & 0,130 & 0,118 & 0,142 & 0,166 & 0,153 & 0,184 & 0,210 \\
\hline
\end{tabular}

Fonte: Resultados da pesquisa.

No tocante as operações de crédito, pode-se dizer que as trajetórias são semelhantes, porém os índices sugerem que a concentração é ainda mais acentuada. Por exemplo, o $\mathrm{CR}_{5}$ demonstra que em 2009, aproximadamente $70 \%$ do mercado de crédito é de domínio dos 5 maiores bancos, apresentando um aumento significativo da participação dessas instituições no comparativo com 2008. O HHI*, por sua vez, demonstra que em 2009 o setor pode ser classificado com concentração levemente moderada, de acordo com a classificação sugerida pelo departamento de justiça norte-americano. 
Tabela 4. Índices de concentração calculados a partir das Operações de Crédito das Instituições Bancárias - Períodos Selecionados.

\begin{tabular}{|l|c|c|c|c|c|c|c|c|c|}
\hline & Dez/90 & Dez/95 & Dez/00 & Dez/02 & Dez/05 & Dez/06 & Dez/07 & Dez/08 & Dez/09 \\
\hline $\mathbf{C R}_{\mathbf{5}}$ & 0,622 & 0,594 & 0,548 & 0,464 & 0,519 & 0,533 & 0,545 & 0,570 & 0,693 \\
\hline $\mathbf{C R}_{\mathbf{1 0}}$ & 0,731 & 0,741 & 0,678 & 0,627 & 0,708 & 0,742 & 0,754 & 0,770 & 0,814 \\
\hline $\mathbf{C R}_{\mathbf{2 0}}$ & 0,834 & 0,829 & 0,806 & 0,782 & 0,848 & 0,859 & 0,868 & 0,886 & 0,903 \\
\hline $\mathbf{H H I}^{*}$ & 0,125 & 0,096 & 0,082 & 0,053 & 0,068 & 0,075 & 0,076 & 0,088 & 0,112 \\
\hline $\mathbf{H T I}$ & 0,048 & 0,043 & 0,039 & 0,036 & 0,046 & 0,049 & 0,051 & 0,056 & 0,067 \\
\hline Theil & 0,569 & 0,579 & 0,644 & 0,699 & 0,655 & 0,641 & 0,635 & 0,613 & 0,569 \\
\hline $\mathbf{C C I}$ & 0,375 & 0,319 & 0,298 & 0,228 & 0,265 & 0,282 & 0,283 & 0,309 & 0,356 \\
\hline $\mathbf{H K I}$ & 7,719 & 9,934 & 11,366 & 16,734 & 13,241 & 12,221 & 12,000 & 10,567 & 8,459 \\
\hline $\mathbf{H}_{\mathbf{m}}$ & 0,297 & 0,258 & 0,224 & 0,170 & 0,209 & 0,224 & 0,230 & 0,252 & 0,304 \\
\hline
\end{tabular}

Fonte: Resultados da pesquisa.

E por fim, apresenta-se a análise dos depósitos totais. O comportamento desse indicador destoa dos demais, na medida em que não se visualiza um declínio na concentração no decorrer da década de 1990. A maioria dos índices se comporta de maneira estável entre dezembro de 1995 e junho de 2008, porém, a partir de então, principalmente os índices CCI e $\mathrm{H}_{\mathrm{m}}$ destacam um elevado aumento na concentração bancária. A análise da razão de concentração $\mathrm{CR}_{5}$ também permite evidenciar essa mudança, em que a participação das 5 maiores instituições bancárias aumentam sua participação de $61,8 \%$ em dezembro de 2007 para 72,3\% em dezembro de 2009.

Tabela 5. Índices de concentração calculados a partir dos Depósitos Totais das Instituições Bancárias - Períodos Selecionados.

\begin{tabular}{|l|c|c|c|c|c|c|c|c|c|}
\hline & Dez/90 & Dez/95 & Dez/00 & Dez/02 & Dez/05 & Dez/06 & Dez/07 & Dez/08 & Dez/09 \\
\hline $\mathbf{C R}_{\mathbf{5}}$ & 0,557 & 0,588 & 0,579 & 0,614 & 0,614 & 0,619 & 0,618 & 0,647 & 0,723 \\
\hline $\mathbf{C R}_{\mathbf{1 0}}$ & 0,687 & 0,718 & 0,713 & 0,795 & 0,795 & 0,815 & 0,820 & 0,846 & 0,850 \\
\hline $\mathbf{C R}_{\mathbf{2 0}}$ & 0,808 & 0,812 & 0,839 & 0,922 & 0,922 & 0,928 & 0,930 & 0,933 & 0,927 \\
\hline
\end{tabular}




\begin{tabular}{|l|c|c|c|c|c|c|c|c|c|}
\hline HHI $^{*}$ & 0,091 & 0,096 & 0,086 & 0,085 & 0,085 & 0,085 & 0,083 & 0,093 & 0,109 \\
\hline HTI & 0,040 & 0,039 & 0,046 & 0,065 & 0,065 & 0,067 & 0,069 & 0,072 & 0,076 \\
\hline Theil & 0,613 & 0,586 & 0,614 & 0,588 & 0,588 & 0,582 & 0,581 & 0,563 & 0,543 \\
\hline $\mathbf{C C I}$ & 0,314 & 0,316 & 0,294 & 0,287 & 0,287 & 0,286 & 0,276 & 0,302 & 0,339 \\
\hline $\mathbf{H K I}$ & 10,453 & 10,040 & 11,007 & 10,936 & 10,936 & 10,899 & 11,194 & 10,073 & 8,651 \\
\hline $\mathbf{H}_{\mathbf{m}}$ & 0,233 & 0,253 & 0,241 & 0,259 & 0,259 & 0,263 & 0,260 & 0,281 & 0,315 \\
\hline
\end{tabular}

Fonte: Resultados da pesquisa.

Ainda sob a luz dos índices de concentração, parte-se para a análise da correlação, buscando evidenciar as semelhanças e particularidades dos diferentes índices utilizados nessa análise. No Quadro 1, pode-se observar que a medida que a Razão de Concentração aumenta, sua correlação com o índice HTI também aumenta. O contrário é válido quando se analisa os índices HHI*, $\mathrm{H}_{\mathrm{m}}$, CCI, HKI e Theil, onde observa-se que, a correlação desses índices com as Razões de Concentração diminuem a medida que o número de firmas consideradas na análise aumenta. Ou seja, a eficácia dos diferentes índices depende do número de firmas bancárias consideradas na análise.

\begin{tabular}{|l|c|c|c|c|c|c|c|c|c|}
\hline & $\mathrm{CR}_{5}$ & $\mathrm{CR}_{10}$ & $\mathrm{CR}_{20}$ & $\mathrm{HHI}^{*}$ & $\mathrm{HTI}$ & $\mathrm{H}_{\mathrm{m}}$ & $\mathrm{CCl}$ & $\mathrm{HKI}$ & Theil \\
\hline $\mathrm{CR}_{5}$ & 1 & & & & & & & & \\
\hline $\mathrm{CR}_{10}$ & 0,823 & 1 & & & & & & & \\
\hline $\mathrm{CR}_{20}$ & 0,498 & 0,878 & 1 & & & & & & \\
\hline $\mathrm{HHI}^{*}$ & 0,951 & 0,738 & 0,466 & 1 & & & & & \\
\hline $\mathrm{HTI}$ & 0,355 & 0,807 & 0,963 & 0,292 & 1 & & & & \\
\hline $\mathrm{H}_{\mathrm{m}}$ & 0,962 & 0,862 & 0,624 & 0,977 & 0,472 & 1 & & & \\
\hline $\mathrm{CCl}$ & 0,936 & 0,726 & 0,453 & 0,998 & 0,276 & 0,972 & 1 & & \\
\hline $\mathrm{HKI}$ & $-0,966$ & $-0,816$ & $-0,549$ & $-0,975$ & $-0,375$ & $-0,983$ & $-0,978$ & 1 & \\
\hline Theil & $-0,958$ & $-0,878$ & $-0,645$ & $-0,963$ & $-0,494$ & $-0,994$ & $-0,961$ & 0,982 & 1 \\
\hline
\end{tabular}

Quadro 1. Correlação entre os Índices de Concentração com base no Patrimônio Líquido*

Fonte: Resultados da Pesquisa.

* As correlações entre os índices de concentração para operações de crédito, ativo e depósito total e mantêm as mesmas características apresentadas para o Patrimônio Líquido, não sendo apresentadas nessa análise. 
Dada a alta correlação com os demais índices, utilizou-se o índice HHI* como representativo, para comparar os resultados obtidos com as diferentes variáveis utilizadas: ativos totais, patrimônio líquido, operações de crédito e depósitos totais. Na comparação entre as variáveis observa-se que, até a implementação do Plano Real todas as variáveis encontravam-se em uma trajetória de queda, ou seja, uma diminuição da concentração, porém, na segunda metade da década de 1990, principalmente os depósitos e os ativos totais seguem caminhos distintos (Figura 3).

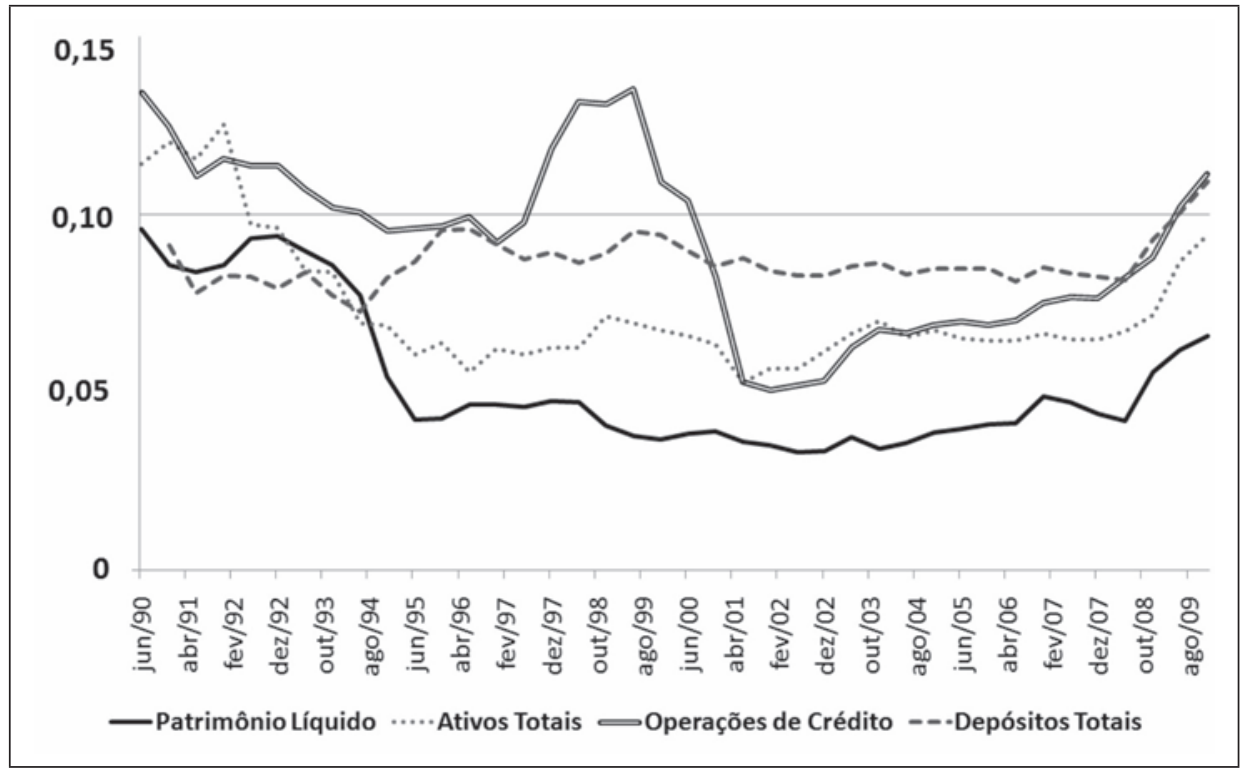

Figura 3. Índice de Hirschman-Herfindal para Ativos Totais, Depósitos Totais, Operações de Crédito e Patrimônio Líquido

Fonte: Resultados da Pesquisa.

O aumento do índice de concentração, entre junho de 1994 e dezembro de 1995, no ativo total, deve-se a redução das receitas de floating e a criação do PROER. Quanto as operações de crédito observa-se um aumento da concentração entre 1997 e 1999. Essa concentração deve-se, em parte aos resultados do PROES, com a aquisição de bancos estaduais e regionais pelos grandes bancos nacionais e de controle estrangeiros. Essa tendência de concentração só se modifica com a crise cambial de 1999, em que, em 
um ambiente de incerteza os bancos reduziram a concessão de crédito, buscando uma composição mais líquida dos seus ativos, e, dada a elevação das taxas de juros, a inadimplência configurou-se como um problema para os bancos nesse período.

Para a década de 2000, tem-se que somente a variável de Depósitos Totais apresentou uma tendência diferente no início da década das demais variáveis, com uma queda acentuada. Esse fato deve-se a postura dos bancos em investir parte de seus ativos em títulos públicos indexados ao câmbio, estratégia que proporcionou aos bancos uma maior proteção com a volatilidade cambial. Essa postura só se modificou com a maxidesvalorização ocorrida no período caracterizado como "crise eleitoral de 2002". Com a criação do empréstimo consignado, há uma retomada na concentração das operações de crédito. Enfim, a concentração ou desconcentração nas operações de crédito é muito suscetível a mudanças na política econômica.

Ao longo da década de 2000 há uma estagnação dos índices de concentração para os Ativos Totais, Operações de Crédito e Patrimônio Líquido. Porém, a partir de junho de 2008 , todas as variáveis analisadas apresentam uma trajetória de concentração. Pode-se sugerir que a fusão dos grandes bancos (Itaú - Unibanco e Santander - ABN Amro) teve influência nesse aumento de concentração, dado que os dados de dezembro de 2008, do Banco Central, já refletem essas fusões.

Por fim, uma última análise que se faz é a exposição das curvas de concentração, que segundo Bikker e Haaf (2002, p. 42) consiste em ordenar as $n$ firmas bancárias por importância relativa e acumular o seu market-share até perfazer $100 \%$ do mercado. Se a curva for representada por uma reta diagonal, significa que cada firma detém a mesma participação relativa, representando um mercado competitivo. Por sua vez, quanto maior for a curvatura, acima dessa reta hipotética, maior é a concentração de mercado. Nota-se que para plotar a curva utiliza-se o market-share acumulado dos bancos, e o fato de haver discrepâncias entre o número de bancos, corrigiu-se supondo que a diferença entre números de bancos seja contabilizada em apenas uma variável. 


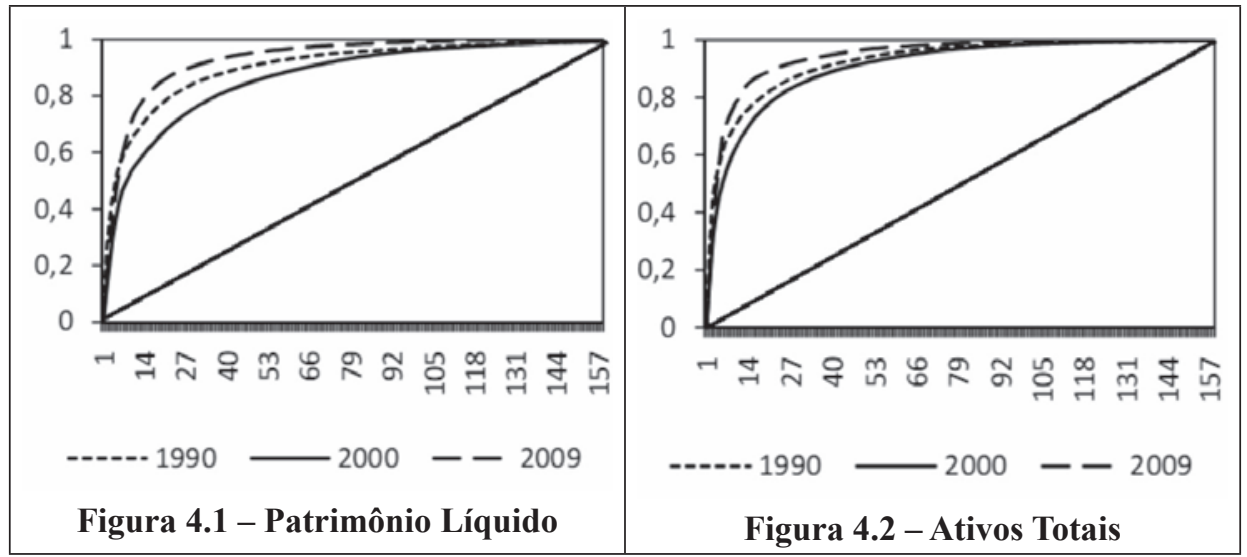

Figura 4. Curva de Concentração para Patrimônio Líquido e Ativos Totais - Anos Selecionados Fonte: Resultados da pesquisa.

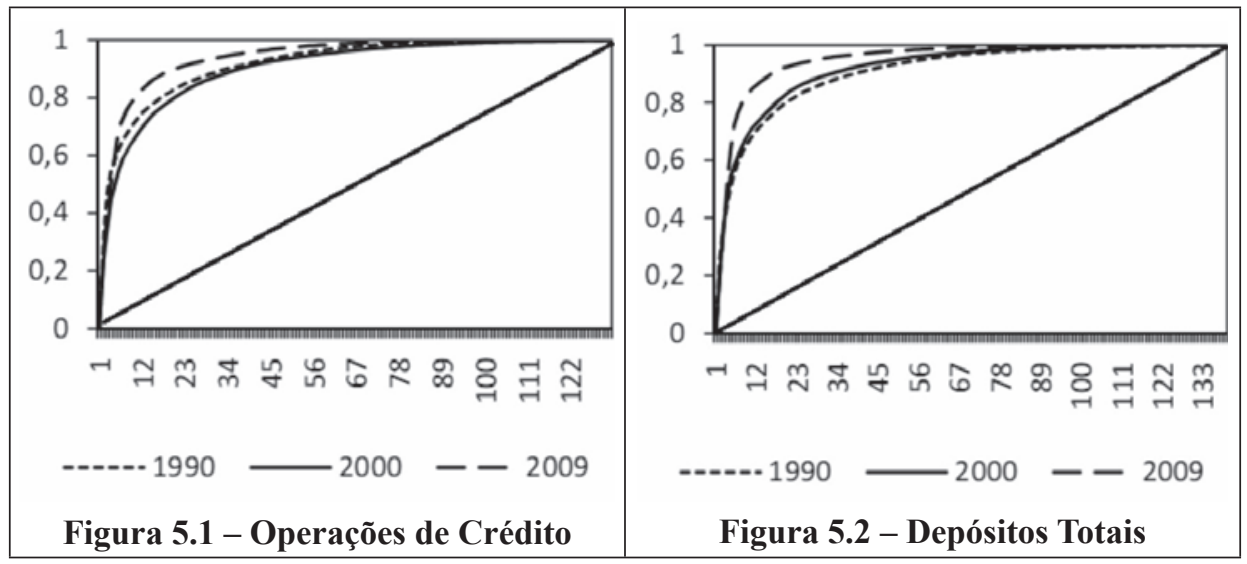

Figura 5. Curva de Concentração para Operações de Crédito e Depósitos Totais - Anos Selecionados Fonte: Resultados da pesquisa.

Observando as curvas de concentração pode-se destacar que para o Patrimônio Líquido, Ativos Totais e as Operações de Crédito a tendência das curvas é similar, observa-se que em 1990 essas três variáveis de análise sugeriam que o sistema financeiro nacional encontrava-se em uma concentração superior ao que fora observada em 2000 porém em patamares inferiores ao ano de 2009. Já para os Depósitos Totais, ao observar a curva de concentração, tem-se que ao decorrer do período de análise há aumentos 
sucessivos na concentração bancária, ou seja, de 1990 para 2000 ocorre uma aumento no grau de concentração do setor, e de 2000 para 2009 esse aumento também ocorre e em escala mais acentuada.

\section{CONCLUSÕES}

No Brasil, antes do Plano Real, o Sistema Financeiro Nacional atuava em uma conjuntura favorável para ganhos com operações de floating e elevados spread, além da regulação precária, a despeito de exigência por parte dos órgãos responsáveis para se abrir um novo banco, por exemplo. Porém, a indústria bancária passou por um processo de profunda transformação, com perdas das fontes de receitas advindas das operações de floating. Apesar das inovações em tecnologia e o corte de pessoal, a fim de diminuir os custos, foi necessária a intervenção do governo para sanear o sistema financeiro.

Com base nos resultados dos índices de concentração analisados, após 1995 os incentivos do governo em consolidar o setor bancário não tiveram impacto significativo quanto ao aumento da concentração do setor. Nesse período, outro fato relevante é de que há uma diminuição gradual da participação de bancos públicos no setor, sugerindo que o governo além de prevenir um risco de quebra sistêmica, atuou "privatizando" o setor bancário, principalmente, com o aumento significativo da participação relativa de bancos com controle e/ou participação estrangeira nas variáveis de análise do presente estudo.

$\mathrm{Na}$ década atual, o setor bancário apresentou algumas especificidades nos índices de concentração. Primeiramente cabe lembrar que a década foi marcada por grandes fusões \& aquisições no setor financeiro, dentre elas pode-se citar a venda de duas instituições públicas de grande porte, a primeira do Banestado para o Itaú em outubro de 2000, e posteriormente o maior banco estadual, o Banespa para o Santander em novembro de 2000, e outras duas grandes fusões foram as que ocorreram recentemente, em dezembro de 2008, que foi a entre o Itaú com o Unibanco e o Santander com o ABN Amro. Essas últimas fusões, contribuíram para o aumento expressivo dos índices de concentração, sugerindo que há um aumento acentuado da concentração bancária no setor financeiro no período recente.

Por fim, pode-se dizer que na década de 1990 a atuação do governo em prevenir e sanar o setor financeiro criou uma indústria financeira forte e 
consolidada ao longo dos anos, fato esse que pode ser visto pela recente crise mundial de 2008, em que não houve uma queda abrupta na quantidade de bancos e/ou uma atuação de caráter emergencial do governo para prevenir algum colapso sistêmico, além de não apresentar, por meio da análise dos dados, um sistema bancário altamente concentrado, em alguns casos pode-se dizer até que os bancos no Brasil atual em um mercado concorrencial.

\section{ANALYSIS OF BANKING COMPETITION IN BRAZIL AFTER THE REAL PLAN}

\section{Abstract}

After the implementation of Plano Real in 1994, the brazilian bank section was affected by deep change because of the adaptation need to the context of low inflation, resulting in loss of the coming incomes of the bank floating. The main happened changes were a wide process of bank consolidation, with coalitions and acquisitions, significant decrease of banks with state control and the facilitation for the entrance of foreign institutions in the national finance market. In order to elucidate such facts concentration indexes and an empiric analysis of data was used, in that it was verified that there was a structural change in the financial industry, in this way, the public section loses great part of it relative participation, in compensation, the private section increased it participation, mainly, with the entrance of foreign banks in the national financial system.

Keywords: Bank concentration, concentration Indexes, Brazilian Bank Section

\section{REFERÊNCIAS}

AVERBUG, A. GIAMBIAGI, F. A Crise Brasileira de 1998/1999 - Origens e Consequências. Rio de Janeiro. BNDES (Texto para Discussão, 77). 2000. Disponível em: <http://www.bndes.gov.br/SiteBNDES/export/sites/ default/bndes_pt/Galerias/Arquivos/conhecimento/td/Td-77.pdf $>$. Acesso em: 14 de Jul. 2010. 
BCB - BANCO CENTRAL DO BRASIL. Ranking dos Bancos: principais contas (balancetes de julho e/ou dezembro). Disponível em: $<$ http://www4. bcb.gov.br/fis/cosif/indrank.asp? idioma=P>. Acesso em: 14 de Jul. 2010.

BCBS - BASLE COMMITTEE ON BANKING SUPERVISION. The New Basle Accord, Third Consultative Document, 2003.

BARBACHAN, J. S. F.; FONSECA, M. F. Concentração Bancária Brasileira: Uma Análise Microeconômica. Financelab Working Paper. IBEMEC. São Paulo. 2004.

BIKKER, J.A.; HAAF, K. Measures of Competition and Concentration in the Banking Industry: A review of the literature, De Nederlandsche Bank, Amsterdam, NL. n. 27, 2002.

BOTELHO, Thiago dos Santos. Concentração Bancária no Brasil e em Portugal. 2006 - Dissertação (Mestrado em Finanças e Economia Empresaria). Escola de Pós-Graduação em Economia (EPGE) - Fundação Getúlio Vargas (FGV), Rio de Janeiro.

CYSNE, R. P.; COSTA, S. G. S. Reflexos do Plano Real sobre o Sistema Bancário Brasileiro. Revista Brasileira de Economia, Rio de Janeiro, v. 51, n. 3, p. 325-346, 1997.

DE PAULA, L. F. R.; Comportamento dos Bancos em Alta Inflação no Brasil: teoria e experiência recente. Tese (Doutorado em Ciência Econômica) - Universidade Estadual de Campinas, Campinas, 1997

. Tamanho, Dimensão e Concentração do Sistema Bancário no Contexto de Alta e Baixa Inflação No Brasil. Nova Economia, Belo Horizonte, v. 8, n. 1, p. 87-116, 1998.

DE PAULA, L. F. R.; MARQUES, Maria Beatriz Leme. Tendências recentes da consolidação bancária no Brasil. Revista Análise Econômica, Porto Alegre, v. 24, n. 45, p. 235-263, 2006. 
FARIA JÚNIOR, J. A.; PAULA, L. F. R.; MARINHO, A. Eficiência do setor bancário brasileiro: a experiência recente das fusões e aquisições. In: Luiz Fernando de Paula; José Luís Oreiro. (Org.). Sistema Financeiro: Uma Análise do Setor Bancário Brasileiro. Rio de Janeiro. Editora Campus-Elsevier. 2007. p. 125-154.

GEORGE, K. D.; JOLL, C. Organização Industrial: Concorrência, Crescimento e Mudança Estrutural. $3^{\mathrm{a}}$ ed. Rio de Janeiro. Editora Zahar, 1983.

GRAU, E. R.; CADE versus BACEN: conflitos de competência entre autarquias e função da Advocacia Geral da União. In: João Carlos de Carvalho Rocha e outros. (Org.). Lei Antitruste. Belo Horizonte: Del Rey, 2005, p. 85-118.

JORGE-NETO, P. M.; ARAUJO, L. A. D.; PONCE, D. A.S. Competição e Concentração entre os Bancos Brasileiros. Economia (Campinas), Brasília, v. 7, n. 3, p. 561-586, 2006.

MAGALHÃES, M. F.; FONSECA, M. V. A.; RUSSO, M.; SANTOS, E. T. Estruturas de Mercado: a Proposta de uma Nova Taxonomia. Sociedade, Contabilidade e Gestão (UFRJ). v. 3. 2008. p.15-27.

MENDONÇA, A. R. R. Regulação prudencial e redes de proteção: transformações recentes no Brasil. Economia Política Internacional: Análise Estratégica n.8, Jan./Jun. 2006

NASSER, A. A. M. Competição e concentração no setor bancário brasileiro atual: estrutura e evolução ao longo do tempo. Trabalho de Conclusão de Curso. (Graduação em Economia) - Universidade de São Paulo, 2008.

PUGA, F. P. Sistema financeiro brasileiro: reestruturação recente, comparações internacionais e vulnerabilidade à crise cambial. Rio de Janeiro. BNDES (Texto para Discussão, 68). 1999.

RESENDE, M. Medidas de Concentração: Uma Resenha. Análise Econômica. 1994. p. 24-33. 
RESENDE, M.; BOFF, H. Concentração Industrial. In: David Kupfer; Lia Hasenclever. (Org.). Economia Industrial: fundamentos teóricos e práticos no Brasil. 2 ed. Rio de Janeiro. Editora Campus, 2002, p. 73-90.

\section{SILVEIRA DATZ, M. D. X. da. Risco Sistêmico e Regulação Bancária} no Brasil. 2002. Dissertação (Mestrado em Economia) - Escola de Pós-Graduação em Economia (EPGE) - Fundação Getúlio Vargas (FGV), Rio de Janeiro. Disponível em: <http://www.race.nuca.ie.ufrj.br/teses/fgv/ Datz,M.pdf>. Acesso em: 08 de Nov. 2010.

Artigo submetido para publicação em janeiro de 2010 e aceito em junho de 2010.

\section{APÊNDICE A - ÍNDICES DE CONCENTRAÇÃO PARA O PATRI- MÔNIO LÍQUIDO (1990 A 2009).}

\begin{tabular}{lccccccccc}
\hline & CR (5) & $\begin{array}{c}\text { CR } \\
\mathbf{( 1 0 )}\end{array}$ & $\begin{array}{c}\text { CR } \\
\mathbf{( 2 0 )}\end{array}$ & HHI* & HTI & Theil & CCI & HKI & Hm \\
\hline jun/90 & 0,5932 & 0,6983 & 0,8029 & 0,0959 & 0,0352 & 0,6143 & 0,3218 & 9,9556 & 0,2476 \\
dez/90 & 0,5555 & 0,6647 & 0,7873 & 0,0858 & 0,0324 & 0,6295 & 0,3022 & 11,0996 & 0,2238 \\
jun/91 & 0,5496 & 0,6691 & 0,7924 & 0,0838 & 0,0325 & 0,6290 & 0,2981 & 11,3573 & 0,2205 \\
dez/91 & 0,5817 & 0,6927 & 0,8023 & 0,0858 & 0,0335 & 0,6142 & 0,2974 & 11,1267 & 0,2332 \\
jun/92 & 0,5720 & 0,6800 & 0,7887 & 0,0934 & 0,0315 & 0,6175 & 0,3174 & 10,2650 & 0,2341 \\
dez/92 & 0,5422 & 0,6519 & 0,7671 & 0,0941 & 0,0286 & 0,6269 & 0,3183 & 10,2103 & 0,2279 \\
jun/93 & 0,5271 & 0,6322 & 0,7525 & 0,0898 & 0,0270 & 0,6381 & 0,3100 & 10,6823 & 0,2194 \\
dez/93 & 0,5271 & 0,6363 & 0,7521 & 0,0857 & 0,0263 & 0,6408 & 0,3019 & 11,1819 & 0,2128 \\
jun/94 & 0,5034 & 0,6200 & 0,7383 & 0,0772 & 0,0249 & 0,6540 & 0,2846 & 12,3591 & 0,1973 \\
dez/94 & 0,4498 & 0,5743 & 0,6996 & 0,0543 & 0,0222 & 0,6948 & 0,2274 & 17,1809 & 0,1569 \\
jun/95 & 0,4136 & 0,5454 & 0,6743 & 0,0422 & 0,0207 & 0,7200 & 0,1809 & 21,6504 & 0,1323 \\
dez/95 & 0,4345 & 0,5647 & 0,6785 & 0,0426 & 0,0208 & 0,7206 & 0,1850 & 21,3581 & 0,1355 \\
jun/96 & 0,4502 & 0,5800 & 0,6917 & 0,0464 & 0,0220 & 0,7096 & 0,1890 & 19,7711 & 0,1454 \\
dez/96 & 0,4578 & 0,5815 & 0,6905 & 0,0464 & 0,0219 & 0,7130 & 0,1881 & 19,7226 & 0,1461 \\
jun/97 & 0,4602 & 0,5843 & 0,6991 & 0,0458 & 0,0224 & 0,7136 & 0,1855 & 19,8854 & 0,1461 \\
dez/97 & 0,4721 & 0,5959 & 0,7119 & 0,0474 & 0,0234 & 0,7102 & 0,1899 & 19,2305 & 0,1515 \\
jun/98 & 0,4688 & 0,5967 & 0,7181 & 0,0472 & 0,0248 & 0,7148 & 0,1904 & 19,1482 & 0,1522 \\
dez/98 & 0,4135 & 0,5945 & 0,7314 & 0,0408 & 0,0261 & 0,7176 & 0,1698 & 21,8584 & 0,1377 \\
jun/99 & 0,4040 & 0,5557 & 0,6946 & 0,0378 & 0,0238 & 0,7359 & 0,1639 & 23,3533 & 0,1276 \\
dez/99 & 0,3876 & 0,5590 & 0,6903 & 0,0369 & 0,0237 & 0,7393 & 0,1608 & 23,8249 & 0,1257 \\
jun/00 & 0,3995 & 0,5703 & 0,7000 & 0,0385 & 0,0241 & 0,7355 & 0,1646 & 22,9358 & 0,1304
\end{tabular}




\begin{tabular}{llllllllll} 
dez/00 & 0,4249 & 0,5524 & 0,6832 & 0,0391 & 0,0232 & 0,7409 & 0,1672 & 22,6238 & 0,1302 \\
jun/01 & 0,3928 & 0,5494 & 0,6927 & 0,0360 & 0,0240 & 0,7436 & 0,1601 & 24,3039 & 0,1233 \\
dez/01 & 0,3849 & 0,5513 & 0,6940 & 0,0352 & 0,0249 & 0,7463 & 0,1576 & 24,6329 & 0,1223 \\
jun/02 & 0,3609 & 0,5460 & 0,7063 & 0,0330 & 0,0265 & 0,7491 & 0,1514 & 25,8320 & 0,1185 \\
dez/02 & 0,3659 & 0,5470 & 0,7167 & 0,0335 & 0,0272 & 0,7478 & 0,1525 & 25,4026 & 0,1206 \\
jun/03 & 0,3932 & 0,5859 & 0,7383 & 0,0374 & 0,0297 & 0,7315 & 0,1592 & 23,0554 & 0,1326 \\
dez/03 & 0,3575 & 0,5587 & 0,7432 & 0,0342 & 0,0296 & 0,7364 & 0,1537 & 24,8973 & 0,1243 \\
jun/04 & 0,3689 & 0,5736 & 0,7510 & 0,0357 & 0,0296 & 0,7330 & 0,1558 & 24,0263 & 0,1284 \\
dez/04 & 0,3820 & 0,5905 & 0,7748 & 0,0387 & 0,0312 & 0,7228 & 0,1647 & 22,3594 & 0,1373 \\
jun/05 & 0,3902 & 0,5942 & 0,7734 & 0,0398 & 0,0316 & 0,7228 & 0,1713 & 21,7810 & 0,1400 \\
dez/05 & 0,3983 & 0,5907 & 0,7715 & 0,0411 & 0,0316 & 0,7201 & 0,1781 & 21,2261 & 0,1424 \\
jun/06 & 0,3940 & 0,5933 & 0,7739 & 0,0413 & 0,0320 & 0,7163 & 0,1760 & 21,1469 & 0,1430 \\
dez/06 & 0,4564 & 0,6578 & 0,8090 & 0,0490 & 0,0361 & 0,6910 & 0,1959 & 18,1623 & 0,1655 \\
jun/07 & 0,4454 & 0,6447 & 0,7991 & 0,0473 & 0,0349 & 0,7006 & 0,1925 & 18,7063 & 0,1604 \\
dez/07 & 0,4309 & 0,6273 & 0,7988 & 0,0440 & 0,0348 & 0,7055 & 0,1813 & 19,9143 & 0,1527 \\
jun/08 & 0,4161 & 0,6063 & 0,7980 & 0,0419 & 0,0348 & 0,7081 & 0,1749 & 20,7966 & 0,1472 \\
dez/08 & 0,4829 & 0,6940 & 0,8389 & 0,0558 & 0,0419 & 0,6641 & 0,2184 & 16,1615 & 0,1844 \\
jun/09 & 0,5160 & 0,7304 & 0,8536 & 0,0618 & 0,0443 & 0,6465 & 0,2339 & 14,7609 & 0,1999 \\
dez/09 & 0,5392 & 0,7394 & 0,8631 & 0,0658 & 0,0469 & 0,6360 & 0,2392 & 13,9276 & 0,2099 \\
\hline
\end{tabular}

Fonte: Resultados da pesquisa.

\section{APÊNDICE B - ÍNDICES DE CONCENTRAÇÃO EM ATIVOS TO- TAIS (1990 A 2009).}

\begin{tabular}{lccccccccc}
\hline & CR (5) & $\begin{array}{c}\text { CR } \\
(\mathbf{1 0})\end{array}$ & $\begin{array}{c}\text { CR } \\
\mathbf{( 2 0 )}\end{array}$ & HHI* & HTI & Theil & CCI & HKI & Hm \\
\hline jun/90 & 0,6059 & 0,7220 & 0,8263 & 0,1144 & 0,0433 & 0,5799 & 0,3556 & 8,42006261 & 0,2791 \\
dez/90 & 0,6112 & 0,7216 & 0,8248 & 0,1206 & 0,0428 & 0,5710 & 0,3659 & 8,01917986 & 0,2866 \\
jun/91 & 0,5970 & 0,7027 & 0,8053 & 0,1156 & 0,0388 & 0,5839 & 0,3570 & 8,35937752 & 0,2741 \\
dez/91 & 0,6112 & 0,7110 & 0,8168 & 0,1255 & 0,0399 & 0,5705 & 0,3734 & 7,72556446 & 0,2883 \\
jun/92 & 0,5504 & 0,6605 & 0,7775 & 0,0973 & 0,0330 & 0,6150 & 0,3240 & 9,87805213 & 0,2372 \\
dez/92 & 0,5535 & 0,6640 & 0,7798 & 0,0963 & 0,0330 & 0,6101 & 0,3213 & 9,98494043 & 0,2392 \\
jun/93 & 0,5292 & 0,6521 & 0,7642 & 0,0842 & 0,0298 & 0,6311 & 0,2972 & 11,3485957 & 0,2179 \\
dez/93 & 0,5322 & 0,6499 & 0,7563 & 0,0839 & 0,0294 & 0,6302 & 0,2959 & 11,4104632 & 0,2171 \\
jun/94 & 0,4852 & 0,6246 & 0,7512 & 0,0693 & 0,0286 & 0,6480 & 0,2644 & 13,6860974 & 0,1889 \\
dez/94 & 0,5001 & 0,6294 & 0,7574 & 0,0687 & 0,0307 & 0,6405 & 0,2572 & 13,7827799 & 0,1927 \\
jun/95 & 0,4823 & 0,6266 & 0,7558 & 0,0605 & 0,0303 & 0,6499 & 0,2336 & 15,5474933 & 0,1780 \\
dez/95 & 0,5053 & 0,6350 & 0,7547 & 0,0640 & 0,0304 & 0,6459 & 0,2423 & 14,7240104 & 0,1863 \\
jun/96 & 0,4779 & 0,5983 & 0,7129 & 0,0556 & 0,0270 & 0,6721 & 0,2238 & 16,77299 & 0,1658 \\
dez/96 & 0,5043 & 0,6224 & 0,7411 & 0,0622 & 0,0296 & 0,6571 & 0,2398 & 15,0776191 & 0,1824 \\
jun/97 & 0,4999 & 0,6150 & 0,7535 & 0,0607 & 0,0303 & 0,6598 & 0,2334 & 15,4113928 & 0,1797
\end{tabular}




\begin{tabular}{|c|c|c|c|c|c|c|c|c|c|}
\hline & & & & & & & & & \\
\hline & & & & & & & & & \\
\hline & & & & & & & & & \\
\hline & & & & & & & & & \\
\hline & 82 & & & & 31 & & & & \\
\hline & & & & & & & & & \\
\hline & & & & & & & & & \\
\hline & & & & & & & & & \\
\hline & & & & & & & & & \\
\hline & 5 & 96 & & & & & & & 765 \\
\hline & & & & & & & & & 374 \\
\hline & & & & & & & & & 990 \\
\hline & & & & & & & & & \\
\hline &, 5217 & & & 54 & & & & & 0,1997 \\
\hline & & & & & & & & & 052 \\
\hline & 5324 & & & & & & & & 028 \\
\hline & & & & & & & & & \\
\hline & 5273 & & & & & & & & 018 \\
\hline & 0,5402 & & & ,0664 & & & & & 111 \\
\hline & 0,5349 & 318 & & 0,06 & & & & & 086 \\
\hline & & & & & & & & & 098 \\
\hline & & & & & & & & & 0,2132 \\
\hline & & & & & & & & & 0,225 \\
\hline & 0,6463 & & & 0,0869 & & & & & 0,2603 \\
\hline & 0.6706 & 0,7969 & 0,8940 & 0,0942 & 588 & 0,5760 & 0,3056 & 10,00 & 0,276 \\
\hline
\end{tabular}

Fonte: Resultados da pesquisa.

\section{APÊNDICE C - ÍNDICES DE CONCENTRAÇÃO EM OPERAÇÕES DE CRÉDITO (1990 A 2009).}

\begin{tabular}{lccccccccc}
\hline & CR (5) & $\begin{array}{c}\text { CR } \\
(\mathbf{1 0 )}\end{array}$ & $\begin{array}{c}\text { CR } \\
\mathbf{( 2 0 )}\end{array}$ & HHI* $^{*}$ HTI & Theil & CCI & HKI & Hm \\
\hline jun/90 & 0,6328 & 0,7451 & 0,8490 & 0,1344 & 0,0515 & 0,56075 & 0,3902 & 7,1832 & 0,3117 \\
dez/90 & 0,6219 & 0,7311 & 0,8344 & 0,1250 & 0,0478 & 0,56928 & 0,3745 & 7,7149 & 0,2966 \\
jun/91 & 0,6005 & 0,7146 & 0,8142 & 0,1109 & 0,0431 & 0,58379 & 0,3490 & 8,6679 & 0,2754 \\
dez/91 & 0,6215 & 0,7322 & 0,8244 & 0,1156 & 0,0437 & 0,56508 & 0,3554 & 8,3573 & 0,2886 \\
jun/92 & 0,6138 & 0,7337 & 0,8369 & 0,1137 & 0,0452 & 0,56332 & 0,3512 & 8,4921 & 0,2873 \\
dez/92 & 0,6101 & 0,7277 & 0,8298 & 0,1139 & 0,0439 & 0,56754 & 0,3522 & 8,4777 & 0,2856 \\
jun/93 & 0,5945 & 0,7203 & 0,8237 & 0,1071 & 0,0420 & 0,57661 & 0,3393 & 9,0013 & 0,2723 \\
dez/93 & 0,5875 & 0,7164 & 0,8145 & 0,1020 & 0,0401 & 0,58257 & 0,3280 & 9,4383 & 0,2631 \\
jun/94 & 0,5834 & 0,7196 & 0,8193 & 0,1006 & 0,0405 & 0,58257 & 0,3258 & 9,5700 & 0,2600
\end{tabular}




\begin{tabular}{|c|c|c|c|c|c|c|c|c|c|}
\hline & & & & & & & & & \\
\hline & & & & & & & & & \\
\hline & & & & & & & & & \\
\hline & & & & & & & & & \\
\hline & & 7013 & 0,8012 & & & & & & \\
\hline & 5830 & 6962 & & & & & & & \\
\hline & 0,5874 & 6715 & & & & & & & \\
\hline & 0,6137 & 7032 & 0,8086 & & & & & & \\
\hline & 0,6131 & 7127 & & & & & & & \\
\hline & 0,6213 & 7214 & & & & & & & \\
\hline & 0,5884 & 7038 & & & & & & & \\
\hline & & 7027 & & & & & & & \\
\hline & 34 & 6777 & & & & & & & \\
\hline & & & & & & & & & \\
\hline & & & & & & & & & \\
\hline & & & & & & & & & \\
\hline & & & & & & & & & \\
\hline & & & & & & & & & \\
\hline & & & & & & & & & \\
\hline & & & & & & & & & \\
\hline & & & & & & & & & \\
\hline & & & & & & & & & \\
\hline & & & & & & & & & \\
\hline & & 16 & & & & & & & \\
\hline & & & & & & & & & \\
\hline & & & & & & & & & \\
\hline & 0,5 & 75 & & & & & & & \\
\hline & & & & & & & & & \\
\hline & 0 & 0 & & & & & & & \\
\hline & & & & & & & & & \\
\hline & & & & & & & & 8,4593 & 303 \\
\hline
\end{tabular}

Fonte: Resultados da pesquisa.

\section{APÊNDICE D - ÍNDICES DE CONCENTRAÇÃO EM DEPÓSITOS TOTAIS - 12/1990 A 12/2009}

\begin{tabular}{lccccccccc}
\hline & CR (5) & $\begin{array}{c}\text { CR } \\
(\mathbf{1 0})\end{array}$ & $\begin{array}{c}\text { CR } \\
(\mathbf{2 0})\end{array}$ & HHI $^{*}$ & HTI & Theil & CCI & HKI & Hm \\
\hline jun/90 & 0,6029 & 0,7317 & 0,8289 & 0,1066 & 0,0448 & 0,5939 & 0,3433 & 8,9769 & 0,2636 \\
dez/90 & 0,5566 & 0,6867 & 0,8078 & 0,0912 & 0,0398 & 0,6134 & 0,3140 & 10,4529 & 0,2332 \\
jun/91 & 0,5299 & 0,6725 & 0,7884 & 0,0780 & 0,0358 & 0,6313 & 0,2855 & 12,1354 & 0,2120
\end{tabular}




\begin{tabular}{|c|c|c|c|c|c|c|c|c|c|}
\hline dez/91 & 0,5379 & 0,6779 & 0,8001 & 0,0827 & 0,0375 & 0,6184 & 0,2955 & 11,5104 & 0,2196 \\
\hline jun/92 & 0,5258 & 0,6677 & 0,7918 & 0,0825 & 0,0360 & 0,6226 & 0,2959 & 11,5361 & 0,2159 \\
\hline 92 & 0,5095 & 0,6601 & 0,7834 & 0,0793 & 0,0342 & 0,6286 & 0,2897 & 11,9907 & 0,2077 \\
\hline & 0,5130 & 0,6705 & 0,7845 & 0,0838 & 0,0338 & 0,6259 & 0,2990 & 11,3820 &, 2144 \\
\hline$z / 93$ & 0,5004 & 0,6567 & 0,7775 & 0,0773 & 0,0326 & 0,6316 & 0,2853 & 12,3060 & 0,2033 \\
\hline & 0,4988 & 0,6524 & 0,7826 & 0,0728 & 0,0331 & 0,6320 & 0,2744 & 13,0302 & 0,1980 \\
\hline & 0,5366 & 0,6894 & 0,8093 & 0,0823 & 0,0383 & 0,6044 & 0,2905 & 5970 & 0,2236 \\
\hline & 0,5503 & 0,6996 & 0,8161 & 0,0867 & 0,0394 &, 5966 & 0,2983 & 0435 & 0,2331 \\
\hline 95 & 0,5883 & 0,7179 & 0,8122 & 0,0957 & 0,0396 & 0,5859 & 0,3156 & 10,0403 & 0,2528 \\
\hline & 0,5829 & 0,7192 & 0,8274 & 0,0958 & 0,0418 & 0,5852 & 0,3189 & 10,0248 & 0,2517 \\
\hline & 0,5817 & 0,7064 & 0,8090 & 0,0916 & 0,0394 & 0,6005 & 0,3117 & 10 & 0,2428 \\
\hline & 0,5783 & 0,6964 & 0,7987 & 0,0875 & 0,0389 & 0,6078 & 017 & 389 & 0,2365 \\
\hline /97 & 0,5760 & 0,6998 & 0,8007 & 0,0894 & 0,0400 & 0,6075 & 0,3053 & 513 & 0,2400 \\
\hline ר/98 & 0,5659 & 0,6933 & 0,7985 & 0,0864 & 0,0401 & 0,6150 & 0,2945 & 10,9826 & 0,2353 \\
\hline 198 & 0,5817 & 0,7073 & 0,8209 & 0,0890 & 0,0433 & 0,6046 & 0,3020 & 10,6764 & 0,2436 \\
\hline & 0,6022 & 0,7213 & 0,8292 & 0,0953 & 0,0460 & 0,5968 & & 736 & 0,2581 \\
\hline 99 & 0,6017 & 0,7236 & & 943 & & & & & 571 \\
\hline ר/00 & 0,5911 & 0,7223 & 0,8409 & 0,0898 & 0,0463 & 0,6053 & 0,3045 & 10,5294 & 0,2489 \\
\hline /00 & 0,5795 & 0,7130 & 0,8391 & 0,0856 & 0,0456 & 0,6143 & 0,2944 & 11,0070 & 0,2407 \\
\hline & 0,5892 & 0,7234 & 0,8477 & 0,0879 & 0,0489 & 0,6068 & 0,2993 & 10,7166 & 0,2465 \\
\hline & & 0,7191 & & & & & & & 0,2405 \\
\hline & 0,5795 & 0,7258 & 0,8568 & 0,0827 & 0,0510 & 0,6181 & 0,2882 & 11,2837 & 0,2396 \\
\hline /02 & 0,5850 & 0,7403 & 0,8731 & 0,0828 & 0,0546 & 0,6113 & 0,2860 & 11,2495 & 0,2429 \\
\hline 03 & 0,5886 & 0,7503 & 0,8748 & 0,0855 & 0,0549 & 0,6098 & 0,2927 & 10,9081 & 0,2489 \\
\hline 103 & 0,5996 & 0,7589 & 0,8826 & 0,0865 & 0,0562 & 0,6056 & & 7916 & 0,2526 \\
\hline & & 0,7574 & 0,8836 & 0,0832 & 0,0556 & 0,6087 & 0,2864 & 11,1823 & 0,2476 \\
\hline /04 & 0,6054 & 0,7791 & 0,9024 & 0,0847 & 0,0602 & 0,5960 & 0,2879 & 10,9941 & 0,2546 \\
\hline$/ 05$ & 0,6121 & 0,7905 & 0,9136 & 0,0848 & 0,0620 & 0,5903 & 0,2837 & 10,9786 & 0,2579 \\
\hline z/05 & 0,6140 & 0,7951 & 0,9223 & 0,0849 & 0,0645 & 0,5883 & 0,2871 & 10,9366 & 0,2595 \\
\hline & 0,6008 & 0,7865 & 0,9138 & 0,0811 & 0,0606 & 0,5951 & 0,2771 & 11,4467 & 0,2496 \\
\hline /06 & 0,6195 & 0,8146 & 0,9275 & 0,0852 & 0,0671 & 0,5824 & 0,2860 & 10,8991 & 0,2629 \\
\hline ר/07 & 0,6086 & 0,8100 & 0,9253 & 0,0835 & 0,0662 & 0,5846 & 0,2811 & 11,1080 & 0,2590 \\
\hline dez/07 & 0,6183 & 0,8200 & 0,9302 & 0,0826 & 0,0691 & 0,5814 & 0,2758 & 11,1941 & 0,2601 \\
\hline$n / 08$ & 0,6107 & 0,8139 & 0,9193 & 0,0814 & 0,0650 & 0,5915 & 0,2719 & 11,3480 & 0,2554 \\
\hline z/08 & 0,6465 & 0,8457 & 0,9330 & 0,0929 & 0,0723 & 0,5626 & 0,3020 & 10,0725 & 0,2812 \\
\hline & 0,6993 & 0,8417 & 0,9250 & 0,1005 & 0,0713 & 0,5544 & 0,3132 & 9,3677 & 0,2976 \\
\hline ez/09 & 0,7227 & 0,8500 & 0,9270 & 0,1093 & 0,0761 & 0,5426 & 0,3397 & 8,6514 & 0,3153 \\
\hline
\end{tabular}

Fonte: Resultados da pesquisa. 